\title{
Erenumab in chronic migraine
}

\section{Patient-reported outcomes in a randomized double-blind study}

Richard B. Lipton, MD, Stewart J. Tepper, MD, Uwe Reuter, MD, Stephen Silberstein, MD, Walter F. Stewart, PhD, Jon Nilsen, PhD, Dean K. Leonardi, PhD, Pooja Desai, PhD, Sunfa Cheng, MD, Daniel D. Mikol, MD, PhD, and Robert Lenz, MD, PhD

Neurology ${ }^{\circledR}$ 2019;92:e2250-e2260. doi:10.1212/WNL.0000000000007452

\section{Abstract}

\section{Objective}

To determine the effect of erenumab, a human monoclonal antibody targeting the calcitonin gene-related peptide receptor, on health-related quality of life (HRQoL), headache impact, and disability in patients with chronic migraine (CM).

\section{Methods}

In this double-blind, placebo-controlled study, 667 adults with CM were randomized (3:2:2) to placebo or erenumab (70 or $140 \mathrm{mg}$ monthly). Exploratory endpoints included migrainespecific HRQoL (Migraine-Specific Quality-of-Life Questionnaire [MSQ]), headache impact (Headache Impact Test-6 [HIT-6]), migraine-related disability (Migraine Disability Assessment [MIDAS] test), and pain interference (Patient-Reported Outcomes Measurement Information System [PROMIS] Pain Interference Scale short form 6b).

\section{Results}

Improvements were observed for all endpoints in both erenumab groups at month 3, with greater changes relative to placebo observed at month 1 for many outcomes. All 3 MSQ domains were improved from baseline with treatment differences for both doses exceeding minimally important differences established for MSQ-role function-restrictive $(\geq 3.2)$ and MSQ-emotional functioning $(\geq 7.5)$ and for MSQ-role function-preventive $(\geq 4.5)$ for erenumab $140 \mathrm{mg}$. Changes from baseline in HIT-6 scores at month 3 were -5.6 for both doses vs -3.1 for placebo. MIDAS scores at month 3 improved by -19.4 days for $70 \mathrm{mg}$ and -19.8 days for $140 \mathrm{mg}$ vs -7.5 days for placebo. Individual-level minimally important difference was achieved by larger proportions of erenumab-treated participants than placebo for all MSQ domains and HIT-6. Lower proportions of erenumab-treated participants had MIDAS scores of severe $(\geq 21)$ or very severe $(\geq 41)$ or PROMIS scores $\geq 60$ at month 3 .

\section{Conclusions}

Erenumab-treated patients with CM experienced clinically relevant improvements across a broad range of patient-reported outcomes.

\section{Clinicaltrials.gov identifier \\ NCT02066415.}

\section{Classification of evidence}

This study provides Class II evidence that for patients with CM, erenumab treatment improves HRQoL, headache impact, and disability.

\author{
Correspondence \\ Dr. Lipton \\ Richard.Lipton@ \\ einstein.yu.edu
}

\section{MORE ONLINE}

$\rightarrow$ Class of Evidence
Criteria for rating
therapeutic and diagnostic
studies
NPub.org/coe

๑ CME Course

NPub.org/cmelist 


\section{Glossary}

CGRP = calcitonin gene-related peptide; $\mathbf{C I}=$ confidence interval; $\mathbf{C M}=$ chronic migraine; $\mathbf{E F}=$ emotional functioning; HIT$\mathbf{6}=$ Headache Impact Test-6; HRQoL = health-related quality of life; MID = minimally important difference; MIDAS = Migraine Disability Assessment; MMD = monthly migraine days; MSQ = Migraine-Specific Quality-of-Life Questionnaire; PREEMPT = Phase 3 Research Evaluating Migraine Prophylaxis Therapy; PRO = patient-reported outcome; PROMIS = Patient-Reported Outcomes Measurement Information System; RFP = role function-preventive; RFR = role functionrestrictive.

Migraine is a disabling neurologic disorder affecting $15 \%$ of the global population. ${ }^{1-5}$ Disability increases progressively with increasing frequency of migraine headache days; patients with chronic migraine (CM), who comprise approximately $10 \%$ of the total migraine population, are most disabled. ${ }^{4,6}$ Migraine and its associated symptoms result in decreased health-related quality of life (HRQoL), social and psychological impact, and increased disability. ${ }^{2,4,7}$ In addition to reducing the frequency, intensity, and duration of attacks, international treatment guidelines state that preventive treatments for migraine should restore ability to function. ${ }^{8}$ Erenumab (in the United States, erenumab-aooe) is a fully human anti-canonical calcitonin gene-related peptide (CGRP) receptor monoclonal antibody approved in the United States for migraine prevention, ${ }^{9}$ with demonstrated clinically relevant efficacy in $\mathrm{CM}^{10}$ The clinical safety and efficacy of erenumab was assessed in a pivotal, randomized, double-blind, placebo-controlled study of patients with CM. Erenumab 70 and $140 \mathrm{mg}$ showed significant reductions from baseline in monthly migraine days compared with placebo (both doses 6.6 days vs placebo 4.2 days) with a safety profile similar to placebo. ${ }^{10}$ Herein, we present a secondary analysis of these clinical trial data to examine the effect of erenumab treatment on multiple patientreported outcomes (PROs) measuring a broad range of complementary outcomes in patients with $\mathrm{CM}$ following 3 months of treatment.

\section{Methods}

The objective of this analysis was to assess the efficacy of erenumab on HRQoL, headache impact, and disability in patients with CM. This study provides Class II evidence that for patients with CM, erenumab treatment improves HRQoL, headache impact, and disability.

\section{Patients and data source}

This was an exploratory analysis of PRO data from a pivotal study that evaluated safety and efficacy of erenumab in patients with $\mathrm{CM}$ ( $\geq 15$ headache days per month, of which $\geq 8$ were migraine days). The eligibility criteria, design, and primary results of the phase 2 study were previously published. ${ }^{10}$ The study comprised 667 participants at 69 study sites worldwide. Participants were randomized to 1 of 3 treatment arms in a 3:2:2 ratio (placebo, erenumab 70 , or erenumab $140 \mathrm{mg}$ monthly) stratified by region (North America vs other) and medication overuse (yes or no) for a 3-month double-blind treatment phase.

\section{Standard protocol approvals, registrations, and patient consents}

The study was approved by an independent ethics committee or local institutional review board at each participating site. Written informed consent was obtained from all enrolled participants. The study was conducted in accordance with the International Conference on Harmonisation Tripartite Guideline on Good Clinical Practice. Clinicaltrials.gov identifier: NCT02066415.

\section{Outcome measures}

\section{Migraine-Specific Quality-of-Life Questionnaire}

The Migraine-Specific Quality-of-Life Questionnaire (MSQ) is a self-administered, migraine-specific, 14-item instrument assessment of quality of life that was developed to assess the effect of migraine on daily functioning across 3 domains. ${ }^{11,12}$ The role function-restrictive (MSQ-RFR) domain measures the effect of migraine on daily social and work-related activities, the role function-preventive (MSQ-RFP) domain assesses whether migraine prevents the individual from performing these activities, and the emotional functioning (MSQ-EF) domain measures emotions associated with migraine. Items are rated on a 6-point scale (none of the time, a little bit of the time, some of the time, a good bit of the time, most of the time, and all of the time). Raw domain scores are summed and transformed to a 100-point scale with higher scores indicating better quality of life and increased scores consistent with improvement. The between-group minimally important difference (MID) for MSQ-RFR is 3.2, for MSQRFP is 4.6, and for MSQ-EF is $7.5 .^{13}$ For within-group analyses for each participant's change with responder analyses, the MID is 5.0 for MSQ-RFR, 5.0-7.9 for MSQ-RFP, and $8.0-10.6$ for MSQ-EF. ${ }^{13}$ In the clinical trial, the MSQ was completed at baseline and then every 4 weeks during the study using an eDiary.

\section{Headache Impact Test- 6}

The Headache Impact Test-6 (HIT-6) is a short-form, selfadministered questionnaire developed as a global measure of adverse headache impact to assess headache severity using widely measured, functionally relevant domains: pain, social and role limitations, cognitive functioning, vitality, and psychological distress. ${ }^{14,15}$ The 6 questions are scored 6, 8, 10, 11, or 13 points based on 5 response categories that assess how often headaches interfere with activities or cause distress (never, rarely, sometimes, very often, or always). Scores for all 
6 items are summed to produce a total HIT-6 score (range: 36-78), interpreted as little or no impact (49 or less), some impact (50-55), substantial impact (56-59), and severe impact (60-78) due to headache with higher scores indicating greater impact and decreased scores consistent with improvement. The between-group MID for HIT-6 in CM is 2.3 points ${ }^{16}$ and the within-patient MID for HIT-6 is a score reduction of 5.0 points. ${ }^{17}$ The recall period for 3 questions is 1 month and the other 3 do not have a specific recall period. The HIT-6 was completed every 4 weeks during the study using an eDiary.

\section{Migraine Disability Assessment test}

The Migraine Disability Assessment (MIDAS) test is a 5-item self-administered questionnaire that sums the number of productive days lost over the past 3 months in the workplace and assesses disability in family, social, and leisure activities at home (e.g., How many days in the last 3 months was the patient at least $50 \%$ disabled at work, home, school, or recreational activities due to migraine?). ${ }^{18}$ In addition to a total score, there are subdomains of absenteeism (missed days, attributable to a headache, from paid work, housework, and nonwork activities) and presenteeism (days at paid work or housework in which productivity was reduced by at least half). MIDAS scores are interpreted as grade I $=0-5$ (minimal or infrequent disability), grade II = 6-10 (mild or infrequent disability), grade III $=11-20$ (moderate disability), grade IVa $=21-40$ and higher (severe disability), grade $\mathrm{IVb}=41$ and higher (very severe disability) with higher scores indicating greater disability and decreased scores consistent with improvement. Although no MID has been established for MIDAS, a preliminary analysis based on an anchor of $25 \%$ change in monthly headache days estimated that an increase or decrease of 5 days of migraine-related disability per 3 months represents meaningful within-patient change. ${ }^{19}$ MIDAS was completed at the end of the 3-month treatment period using an eDiary.

\section{Pain Interference Scale short form $\mathbf{6 b}$}

The Patient-Reported Outcomes Measurement Information System (PROMIS) Pain Interference Scale short form $6 \mathrm{~b}$ is a 6-item instrument that measures the level of pain interference on enjoyment of life, ability to concentrate, dayto-day activities, enjoyment of recreational activities, doing activities away from home, and socializing with others. ${ }^{20}$ Each question is scored on a 5-point scale, summed, and translated into a $t$ score or standardized score with a mean of 50 (average for the US general population) and an SD of 10. The transformed PROMIS Pain Interference $6 \mathrm{~b}$ short form $t$ scores range from 41 to 78.3 with higher scores indicating greater interference and decreased scores consistent with improvement. No MID has been established for the PROMIS Pain Interference Scale for patients with migraine. The recall period used was the past 7 days, and participants completed the PROMIS Pain Interference Scale short form weekly during the study using the eDiary.

\section{Statistical analysis}

Descriptive analyses were conducted reporting the change from baseline and proportion of patients achieving clinically relevant changes from baseline. Descriptive comparisons between erenumab groups and placebo are reported as differences in change from baseline or odds ratios, respectively. Changes from baseline in PRO scores were preplanned exploratory endpoints. Dichotomized endpoints were post hoc exploratory endpoints. Differences in MSQ HIT-6, and PROMIS scores were assessed based on a generalized linear mixed model including treatment, visit, treatment by visit interaction, stratification factors (region and medication overuse), and baseline value as covariates and assuming a firstorder autoregressive covariance structure. There was no imputation for missing data. Differences in MIDAS scores were assessed based on an analysis of covariance model including treatment, stratification factors (region and medication overuse), and baseline value as covariates. MSQ subdomains and HIT-6 were dichotomized based on respective MIDs (MSQ-RFR $\geq 5$, MSQ-RFP $\geq 5$, MSQ-EF $\geq 8$, HIT-6 $\geq 5$ ), PROMIS was dichotomized based on 1 SD worse than the average US general population $(\geq 60)$, and MIDAS was dichotomized based on severe $(\geq 21)$ and very severe $(\geq 41)$ ratings. The randomization analysis set included all participants who were randomized in the study. The efficacy analysis set included participants who received $\geq 1$ dose of randomized treatment and completed at least one postbaseline monthly eDiary measurement. No formal hypothesis was tested. The $p$ values for the difference between erenumab dose groups and placebo were not adjusted for multiple comparisons.

\section{Data availability}

Qualified researchers may request data from Amgen clinical studies. Complete details are available at amgen.com/ datasharing.

\section{Results}

\section{Participants and baseline}

Of 667 participants randomized, 83\% were female with a mean (SD) age of 42 (11) years (table 1). Mean duration since first migraine diagnosis was 22 (12) years and participants had a mean 18.0 (4.6) monthly migraine days and 20.8 (3.9) monthly headache days during the baseline period (table 1). Baseline PRO scores, which were similar among treatment groups, were reflective of the severe effect of migraine (table 1 ).

\section{Changes in PRO score over time}

\section{MSQ scores}

MSQ scores at baseline were similar among treatment groups and were indicative of substantial limitations to daily social and work-related activities with scores of approximately 45, 60, and 53 for MSQ-RFR, MSQ-RFP, and MSQ-EF, respectively (table 1). At month 3 , increases from baseline (improvements) in all $3 \mathrm{MSQ}$ domain scores were greater in the erenumab groups compared with placebo (figure 1). The least-squares mean (95\% confidence interval [CI]) changes 
Table 1 Demographics and baseline disease characteristics

\begin{tabular}{|c|c|c|c|}
\hline & \multirow[b]{2}{*}{ Placebo $(n=286)$} & \multicolumn{2}{|l|}{ Erenumab } \\
\hline & & $70 \mathrm{mg}(\mathrm{n}=191)$ & $140 \mathrm{mg}(\mathrm{n}=190$ \\
\hline Age, y & $42.1(11.3)$ & $41.4(11.3)$ & $42.9(11.1)$ \\
\hline Sex, female, n (\%) & $226(79)$ & $166(87)$ & $160(84)$ \\
\hline Race, white, n (\%) & $268(94)$ & $176(92)$ & $184(97)$ \\
\hline History of prophylactic failure, $n$ (\%) & $200(70)$ & $127(67)$ & $126(66)$ \\
\hline Failed $^{a} \geq 2$ medications & $142(50)$ & $93(49)$ & $92(48)$ \\
\hline Ever used topiramate (yes), $n(\%)$ & $150(52)$ & $89(47)$ & $97(51)$ \\
\hline Ever used onabotulinumtoxinA (yes), n (\%) & $65(23)$ & $50(26)$ & $43(23)$ \\
\hline \multicolumn{4}{|l|}{ Baseline period } \\
\hline Monthly migraine days & $18.2(4.7)$ & $17.9(4.4)$ & $17.8(4.7)$ \\
\hline Monthly headache days & $21.1(3.9)$ & $20.5(3.8)$ & $20.7(3.8)$ \\
\hline Monthly migraine attacks & $4.2(1.7)$ & $4.5(1.7)$ & $4.3(1.6)$ \\
\hline Monthly acute migraine-specific medication use, $d$ & $9.5(7.6)$ & $8.8(7.2)$ & $9.7(7.0)$ \\
\hline Acute migraine-specific medication use, $\mathbf{n}(\%)$ & $225(79)$ & $143(75)$ & $149(78)$ \\
\hline Baseline patient-reported outcome scores ${ }^{b}$ & $n=281$ & $n=188$ & $n=187$ \\
\hline \multicolumn{4}{|l|}{ MSQ, range $0-100$} \\
\hline Role function-restrictive & $42.8(17.6)$ & $44.7(18.3)$ & $45.6(19.1)$ \\
\hline Role function-preventive & $60.3(20.0)$ & $61.9(21.6)$ & $62.9(21.1)$ \\
\hline Emotional functioning & $53.0(25.8)$ & $53.6(25.3)$ & $56.7(26.6)$ \\
\hline HIT-6 total score, range $36-78$ & $63.3(5.2)$ & $63.4(5.0)$ & $62.7(5.6)$ \\
\hline \multicolumn{4}{|l|}{ MIDAS (last 3 mo before study) } \\
\hline Total score & $68.0(56.0)$ & $65.8(45.8)$ & $60.9(52.2)$ \\
\hline Presenteeism & $33.3(28.4)$ & $30.3(24.4)$ & $28.4(25.9)$ \\
\hline Absenteeism & $34.7(33.9)$ & $35.5(32.2)$ & $32.5(35.7)$ \\
\hline PROMIS Interference, range 41-78.3 & $63.9(4.1)$ & $63.2(4.5)$ & $63.4(4.8)$ \\
\hline \multicolumn{4}{|c|}{$\begin{array}{l}\text { Abbreviations: HIT-6 = Headache Impact Test-6; MIDAS = Migraine Disability Assessment; MSQ = Migraine-Specific Quality-of-Life Questionnaire; PROMIS = } \\
\text { Patient-Reported Outcomes Measurement Information System. } \\
\text { Data represent mean (SD) unless otherwise indicated. Randomization analysis set used for analysis. } \\
\text { a Failure attributable to lack of efficacy or adverse events. } \\
\text { b Efficacy analysis set used for analysis. }\end{array}$} \\
\hline
\end{tabular}

from baseline in MSQ-RFR were $17.7(14.9,20.6)$ for $70 \mathrm{mg}$ and $19.1(16.3,22.0)$ for $140 \mathrm{mg}$ vs $11.8(9.4,14.1)$ for placebo. Respective changes for MSQ-RFP were 13.0 (10.5, $15.6)$ and $13.8(11.3,16.4)$ vs $8.9(6.8,11.0)$ and for MSQ-EF were $18.2(15.0,21.3)$ and $18.8(15.6,21.9)$ vs $9.9(7.3,12.5)$. These differences from placebo were observed at the earliest time point assessed, month 1 , and were observed throughout the double-blind period (figure 1). At month 3 , the differences between the erenumab groups and placebo exceeded the established group-level MID for all MSQ domains for both doses except for MSQ-RFP with the erenumab 70-mg group (figure 1). At month 3, a greater proportion of participants in the erenumab group than in the placebo group had changes in MSQ scores that exceeded the within-patient MID for all 3 subdomains (table 2). There were moderately negative linear relationships between change in MSQ scores and change in monthly migraine days (MMD) (correlation coefficient $r$ values ranged from -0.61 to -0.45 in the active treatment groups) that were significantly different from zero $(p<0.001)$ (figures 4, A-C).

\section{HIT-6 scores}

Mean total HIT- 6 score at baseline, similar among treatment groups, was approximately 63 (table 1), reflective of severe 

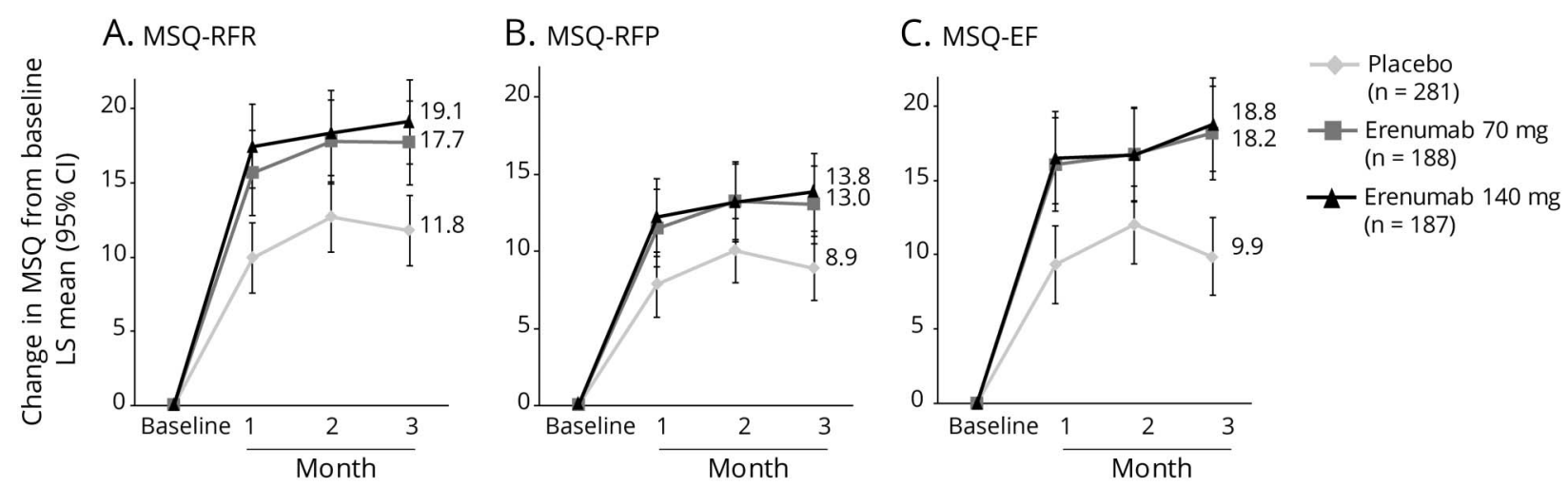

Difference in LS mean from placebo (95\%)

$\begin{array}{rrr}9.4) & 5.1(1.4,8.8) & 6.0(2.3,9.6) \\ .002 & p=0.007 & p=0.002 \\ 11.2) & 5.7(2.0,9.4) & 7.4(3.7,11.0)\end{array}$

Group-level MID $\geq 4.5$

$3.7(0.4,6.9) \quad 3.3(0.0,6.5) \quad 4.1(0.9,7.4)$

$p=0.028 \quad p=0.051 \quad p=0.013$

$4.4(1.1,7.6) \quad 3.1(0.2,6.4) \quad 4.9(1.7,8.2)$

$\begin{array}{rrr}p=0.009 \quad p=0.061 & p=0.003\end{array}$

\section{Group-level MID $\geq 7.5$}

$\begin{array}{rrr}6.8(2.7,10.8) & 4.8(0.7,8.8) & 8.3(4.3,12.4) \\ p=0.028 & p=0.051 & p=0.013\end{array}$

$7.2(3.2,11.3) \quad 4.7(0.7,8.8) \quad 8.9(4.9,13.0)$

$p<0.001 \quad p=0.023 \quad p<0.001$

Least-squares (LS) mean changes from baseline in (A) MSQ-role function-restrictive (MSQ-RFR), (B) MSQ-role function-preventive (MSQ-RFP), and (C) MSQ-emotional functioning (MSQ-EF) scores among participants with chronic migraine who were assigned to receive erenumab 70 mg, erenumab 140 mg, or placebo every month. The error bars represent $95 \%$ confidence intervals (Cls). Figure based on the efficacy analysis set. All $p$ values $\leq 0.05$, except for MSQ-RFP at month 2: erenumab $70 \mathrm{mg}, p=0.051$, and erenumab $140 \mathrm{mg}, p=0.061$. MID = minimally important difference.

impact of headaches (>60). At month 3, mean (SE) HIT-6 scores were $57.6(0.5)$ for $70 \mathrm{mg}$ and $57.0(0.6)$ for $140 \mathrm{mg}$ vs $60.2(0.4)$ for placebo and reflected greater changes from baseline. The change from baseline in total HIT-6 score was greater in the erenumab groups than in placebo as early as month 1 and was sustained throughout the double-blind period (figure 2). The least-squares mean ( $95 \% \mathrm{CI})$ changes from baseline at month 3 in HIT-6 were $-5.6(-6.5,-4.6)$ for both $70 \mathrm{mg}$ and $140 \mathrm{mg}$ vs $-3.1(-3.9,-2.3)$ for placebo. The between-group HIT-6 MID ( $\geq 1.5$ points) was achieved at months 2 and 3 for both doses and by month 1 for $140 \mathrm{mg}$ erenumab. A greater proportion of erenumab-treated participants than placebo achieved the withinpatient MID for HIT-6 (score reduction of $\geq 5$ points) at month 3 , indicating improvement (table 2 ). There was a moderately positively linear relationship between change in HIT-6 score and change in $\mathrm{MMD}$ (correlation coefficient $r$ values ranged from 0.53 to 0.62 in the active treatment groups) that were significantly away from zero $(p<0.001)$ (figure 4D).

\section{MIDAS scores}

MIDAS scores at baseline indicated severe disability; at baseline, $81.9 \%$ of participants had MIDAS scores of $\geq 21$ (severe disability) and $61.4 \%$ had scores of $\geq 41$ (very severe disability). Reductions from baseline to month 3 in MIDAS total, absenteeism, and presenteeism scores were greater in the erenumab groups as compared with placebo, indicating better improvement (figure 3). The least-squares mean (95\% CI) changes from baseline in MIDAS total scores were -19.4 $(-25.2,-13.6)$ for $70 \mathrm{mg}$ and $-19.8(-25.6,-14.0)$ for $140 \mathrm{mg}$ vs $-7.5(-12.4,-2.7)$ for placebo. Respective changes for absenteeism were $-10.3(-13.6,-6.9)$ and $-10.2(-13.6$, $-6.8)$ vs $-5.2(-8.0,-2.4)$ and for presenteeism were -9.3
$(-12.6,-6.1)$ and $-9.9(-13.2,-6.7)$ vs $-1.9(-4.7,0.8)$. At month 3 , a lower proportion of participants in the erenumab groups had MIDAS scores $\geq 21$ compared with placebo (table 2 ). Likewise, the proportion of participants with MIDAS scores $\geq 41$ was lower in the erenumab groups than in the placebo group (table 2). There was a moderately positive linear relationship between change in MIDAS score and change in total migraine days over the 12-week double-blind treatment phase (correlation coefficient $r$ values ranged from 0.34 to 0.44 in the active treatment groups) that were significantly away from zero $(p<0.001)$ (figure $4 \mathrm{E}$ ).

\section{PROMIS scores}

PROMIS scores at baseline (mean 63.4) suggested participants had pain interference $>1$ SD worse than the average US general population. At month 3, decreases in PROMIS scores were greater (better) in the erenumab groups as compared with placebo (figure 5). The least-squares mean (95\% CI) changes from baseline in PROMIS scores were -6.5 (-7.4, -5.6) for $70 \mathrm{mg}$ and $-7.1(-8.0,-6.2)$ for $140 \mathrm{mg}$ vs $-4.5(-5.2,-3.8)$ for placebo. The response to erenumab $140-\mathrm{mg}$ dosage was observed as early as month 1 . At month $3,50.0 \%$ of participants in the placebo group, compared with $32.5 \%$ and $34.2 \%$ of erenumab 70 and $140 \mathrm{mg}$, had PROMIS scores $\geq 60$ (table 2).

\section{Discussion}

$\mathrm{CM}$ is a severely disabling disease associated with poor HRQoL as a result of headache, associated symptoms, and comorbidities. ${ }^{1,4,6}$ Currently, there are few evidenced-based treatment options that patients can use to manage CM. 
Table 2 Patient-reported outcome responder rates at month 3

\begin{tabular}{|c|c|c|c|}
\hline & \multirow[b]{2}{*}{ Placebo $(n=281)$} & \multicolumn{2}{|l|}{ Erenumab } \\
\hline & & $70 \mathrm{mg}(\mathrm{n}=188)$ & $140 \mathrm{mg}(\mathrm{n}=187)$ \\
\hline \multicolumn{4}{|l|}{ MSQ } \\
\hline MSQ-RFR ( $\geq 5$ increase from baseline) & $162(61.6)$ & $125(69.4)$ & $131(73.6)$ \\
\hline Adjusted odds ratio $(95 \% \mathrm{Cl})^{\mathrm{a}}$ & & $1.9(1.1,3.3)$ & $2.8(1.6,4.9)$ \\
\hline$p$ Value $^{\mathrm{b}}$ & & 0.031 & $<0.001$ \\
\hline MSQ-RFP ( $\geq 5$ increase from baseline) & $162(61.6)$ & $120(66.7)$ & $121(68.0)$ \\
\hline Adjusted odds ratio $(95 \% \mathrm{Cl})^{\mathrm{a}}$ & & $1.5(0.9,2.6)$ & $1.6(0.9,2.8)$ \\
\hline$p$ Value $^{\mathrm{b}}$ & & 0.13 & 0.085 \\
\hline MSQ-EF ( $\geq 8$ increase from baseline) & $122(46.4)$ & $108(60.0)$ & $102(57.3)$ \\
\hline Adjusted odds ratio $(95 \% \mathrm{Cl})^{\mathrm{a}}$ & & $2.4(1.4,4.3)$ & $2.4(1.4,4.3)$ \\
\hline$p$ Value $^{\mathrm{b}}$ & & 0.003 & 0.003 \\
\hline HIT-6 total score ( $\geq 5$ decrease from baseline) & $80(30.5)$ & $89(49.4)$ & $84(47.2)$ \\
\hline Adjusted odds ratio $(95 \% \mathrm{Cl})^{\mathrm{a}}$ & & $2.3(1.5,3.4)$ & $2.3(1.5,3.4)$ \\
\hline$p$ Value $^{\mathrm{b}}$ & & $<0.001$ & $<0.001$ \\
\hline \multicolumn{4}{|l|}{ MIDAS (severe or very severe disability) } \\
\hline$\geq 21$ (severe) & $202(77.7)$ & $112(62.9)$ & $98(55.7)$ \\
\hline Adjusted odds ratio $(95 \% \mathrm{Cl})^{\mathrm{c}}$ & & $0.4(0.3,0.7)$ & $0.4(0.2,0.6)$ \\
\hline$p$ Value $^{b}$ & & $<0.001$ & $<0.001$ \\
\hline$\geq 41$ (very severe) & $143(55.0)$ & $72(40.4)$ & 65 (36.9) \\
\hline Adjusted odds ratio $(95 \% \mathrm{Cl})^{\mathrm{C}}$ & & $0.5(0.3,0.8)$ & $0.5(0.3,0.7)$ \\
\hline$p$ Value $^{b}$ & & 0.002 & $<0.001$ \\
\hline PROMIS ( $\geq 60)$ & $121(50.0)$ & $53(32.5)$ & $54(34.2)$ \\
\hline Adjusted odds ratio $(95 \% \mathrm{Cl})^{\mathrm{a}}$ & & $0.3(0.2,0.7)$ & $0.3(0.1,0.6)$ \\
\hline$p$ Value $^{b}$ & & 0.003 & $<0.001$ \\
\hline
\end{tabular}

Abbreviations: $\mathrm{Cl}$ = confidence interval; $\mathrm{EF}=$ emotional functioning; HIT-6 = Headache Impact Test-6; MIDAS = Migraine Disability Assessment; MSQ = Migraine-Specific Quality-of-Life Questionnaire; PROMIS = Patient-Reported Outcomes Measurement Information System; RFP = role function-preventive; $\mathrm{RFR}=$ role function-restrictive.

Data represent $\mathrm{n}(\%)$. Efficacy analysis set used for analysis.

${ }^{a}$ Adjusted odds ratios and $p$ values are obtained from a generalized linear mixed model with logit link. Model includes treatment, visit, treatment by visit, stratification factors region and medication overuse, and baseline value as covariates and assumes a first-order autoregressive covariance structure.

${ }^{\mathrm{b}}$ The $p$ values for pairwise comparisons are nominal $p$ values without multiplicity adjustment.

${ }^{c}$ Adjusted odds ratios and $p$ values are obtained from a logistic regression model that includes treatment, stratification factors region and medication overuse, and baseline value as covariates.

Erenumab is effective in reducing monthly migraine days in patients with $\mathrm{CM} .{ }^{10}$ Both erenumab 70 and $140 \mathrm{mg}$ reduced monthly migraine days by 6.6 days compared with 4.2 days for placebo (mean treatment difference -2.5$).{ }^{10}$ PROs are designed to capture the effect of migraine beyond simple counts of migraine days and can be used to more completely represent the patient perspective and experience. PROs provide context to more fully characterize the effect of illness and the benefits of treatment.

HIT-6 and MIDAS, the most frequently used PRO instruments in headache studies, measure headache impact and migraine-specific disability. HIT-6 assesses headache severity by determining how often headaches interfere with activities or cause distress, whereas MIDAS measures the number of productive days lost, and the MSQ assesses the effect of migraine on daily functioning. The mean total HIT-6 score of approximately 63 is reflective of the severe impact of headaches $(>60)$, consistent with the $61 \%$ of patients with MIDAS scores $\geq 41$ (very severe disability). Likewise, the baseline MSQ scores were reflective of substantial impairments in migraine-specific quality of life. In contrast to the headachespecific measures, PROMIS is a more generic instrument, 
Figure 2 Change in Headache Impact Test-6 (HIT-6) total score from baseline over 3 months

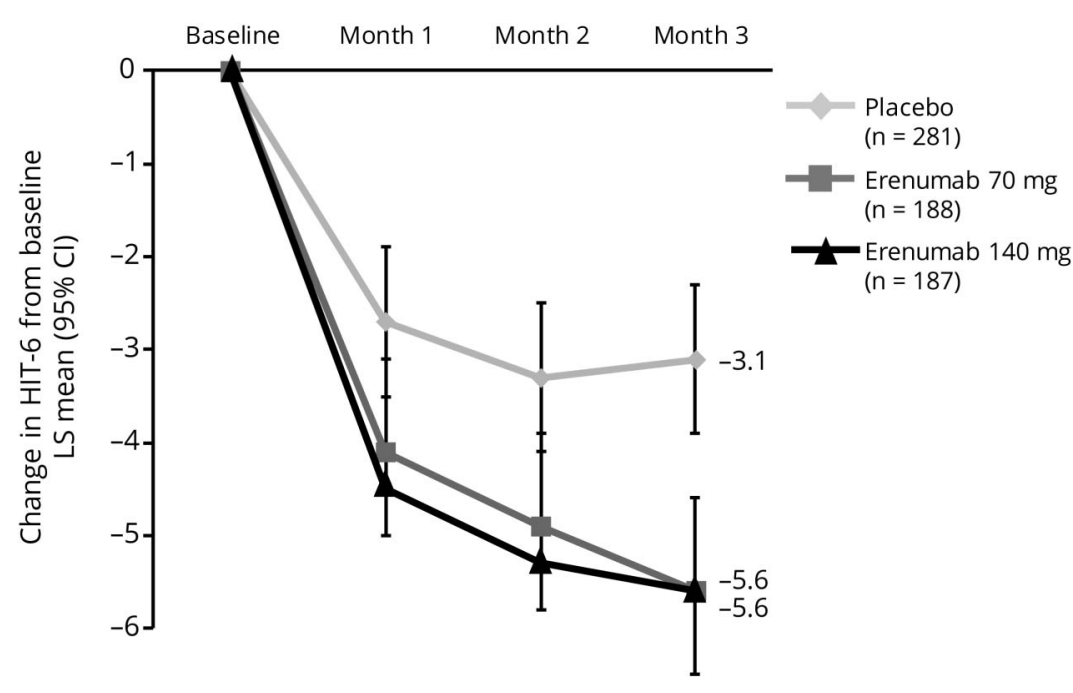

Differences in LS mean from placebo $(95 \% \mathrm{Cl})$

(Group-level MID $\geq 1.5$ )

$\begin{array}{rrrr}70 \mathrm{mg} & -1.4(-2.6,-0.2) & -1.6(-2.8,-0.4) & -2.5(-3.7,-1.2) \\ & p=0.025 & p=0.011 & p<0.001 \\ 140 \mathrm{mg} & -1.8(-3.1,-0.6) & -2.0(-3.3,-0.8) & -2.5(-3.7,-1.2) \\ & p=0.004 & p=0.001 & p<0.001\end{array}$

Least-squares (LS) mean changes from baseline in HIT-6 scores among participants with chronic migraine who were assigned to receive erenumab $70 \mathrm{mg}$, erenumab $140 \mathrm{mg}$, or placebo every month. The error bars represent $95 \%$ confidence intervals (Cls). Figure based on the efficacy analysis set. All $p$ values $\leq 0.05$. MID $=$ minimally important difference. which measures pain interference and allows for comparison with other disease states and the general population. PROMIS scores at baseline (mean 63.4) suggested that participants had pain interference $>1$ SD worse than the average US general population. Although each of the PRO measures different aspects of patient well-being, the convergence of the results indicated how severely CM affected these patients and similar to findings of prior CM studies. ${ }^{16,21}$
The PRO results from this pivotal study showed consistent benefits of erenumab with improvement across a broad set of PROs measuring a range of complementary outcomes. The observed treatment effect on these outcomes exceeded the established clinically meaningful between-group minimum difference for all measures with established MIDs. Moreover, with one exception (i.e., MSQ-RFP), significantly larger percentages of participants achieved clinically meaningful

Figure 3 Change in Migraine Disability Assessment (MIDAS) scores from baseline to month 3

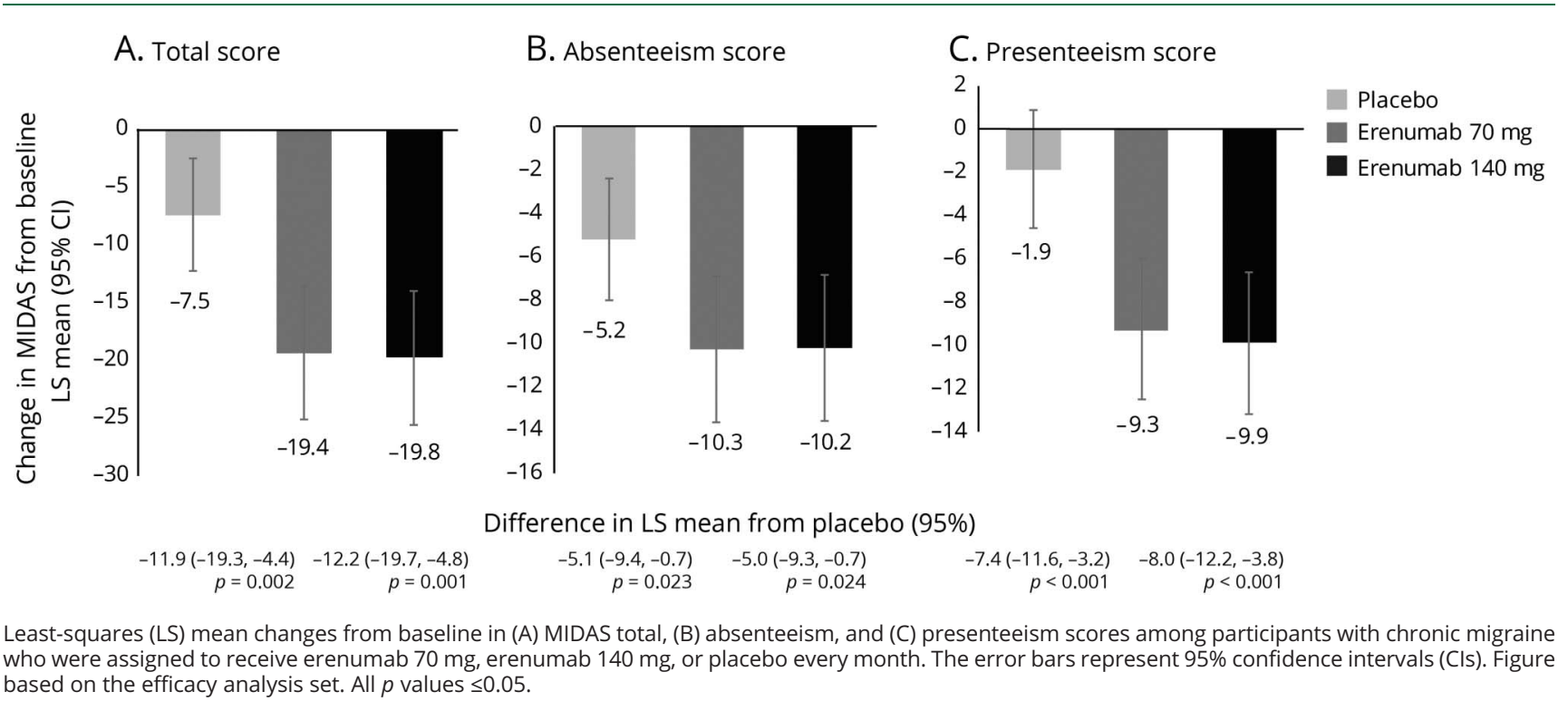



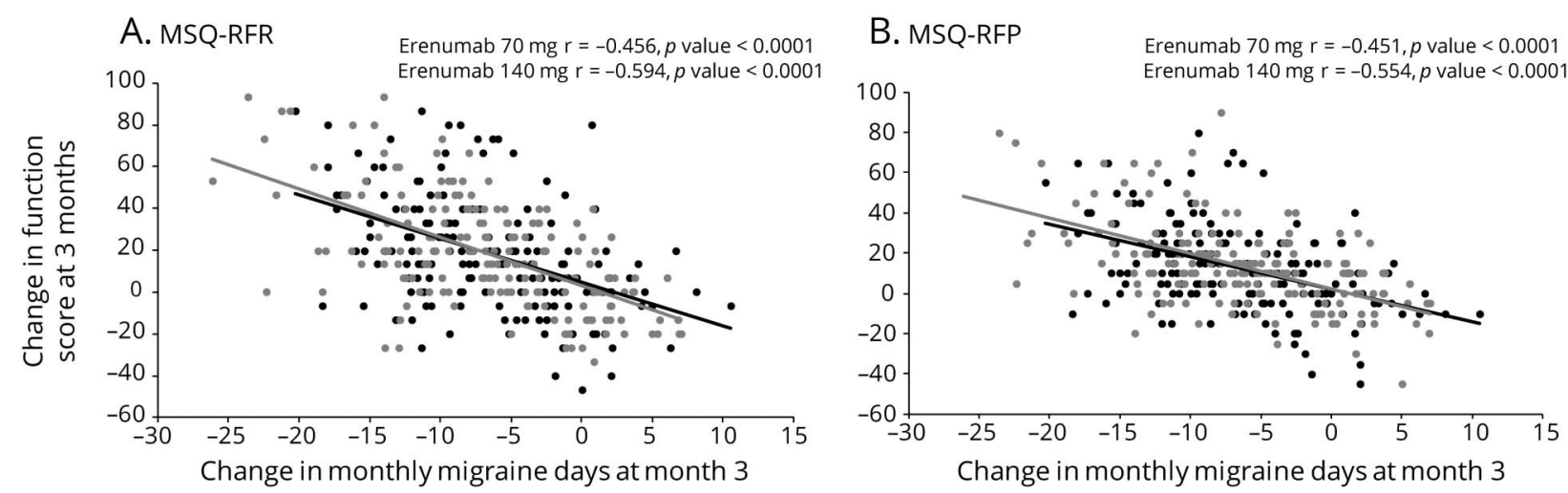

\section{MSQ-EF}
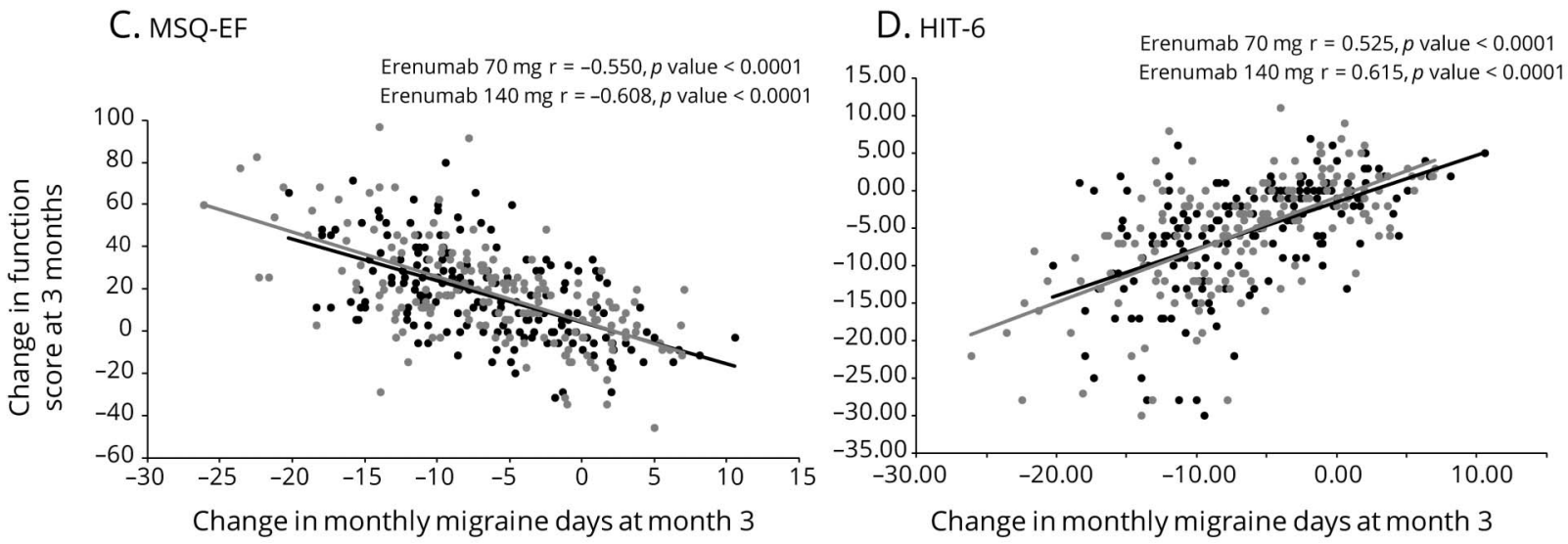

\section{E. MIDAS}

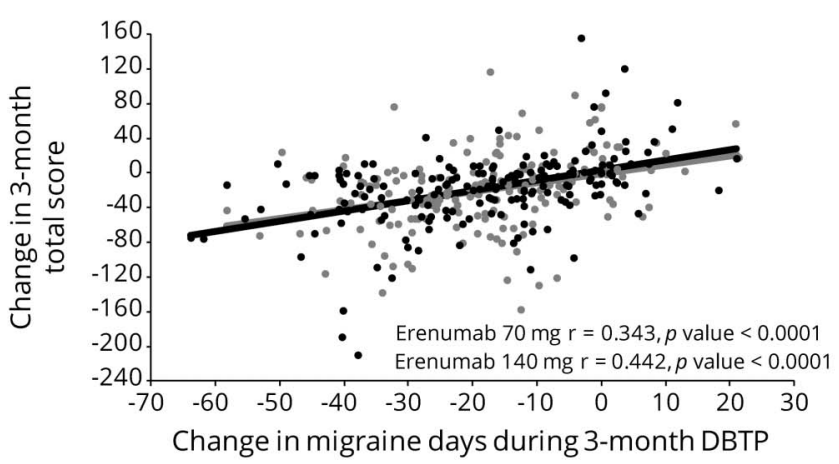

- Erenumab $70 \mathrm{mg}$

- Erenumab $140 \mathrm{mg}$

- Erenumab $70 \mathrm{mg}$

— Erenumab $140 \mathrm{mg}$

(A) Migraine-Specific Quality-of-Life Questionnaire-role function-restrictive (MSQ-RFR), (B) Migraine-Specific Quality-of-Life Questionnaire-role functionpreventive (MSQ-RFP), (C) Migraine-Specific Quality-of-Life Questionnaire-emotional functioning (MSQ-EF), (D) Headache Impact Test-6 (HIT-6), and (E) Migraine Disability Assessment (MIDAS).

improvements in all measures. ${ }^{16}$ Compared with patients who reported no change, patients who reported feeling "somewhat better" had HIT-6 scores differing by 2.3 points, which was considered evidence of clinically meaningful improvement. ${ }^{16}$ This threshold was achieved at months 2 and 3 for both doses and by month 1 for $140 \mathrm{mg}$ erenumab. Similarly, differences from baseline in MIDAS total score were $>5$ days, indicative of a clinically meaningful change. ${ }^{19}$ These treatment benefits emerged early, detected at the first 1-month posttreatment assessment (the earliest time point measured). Treatment benefits were sustained through the 3-month double-blind phase.
Although improvements in PRO scores correlated with reduction in migraine frequency with erenumab treatment, the proportion of patients achieving an MID with the PROs in this analysis was higher than the proportion of patients achieving a $\geq 50 \%$ reduction in MMD. The $50 \%$ threshold (e.g., for reduction in migraine or headache days) is an arbitrary way to dichotomize clinical response/nonresponse, and although widely used in practice and as a clinical trial endpoint, it has been shown that response at a 30\% threshold can be clinically meaningful for patients with $\mathrm{CM}^{22}$ Achievement of a $50 \%$ response has no direct relationship to the MIDs of 
Figure 5 Change in Patient-Reported Outcomes Measurement Information System (PROMIS) scores from baseline over 3 months

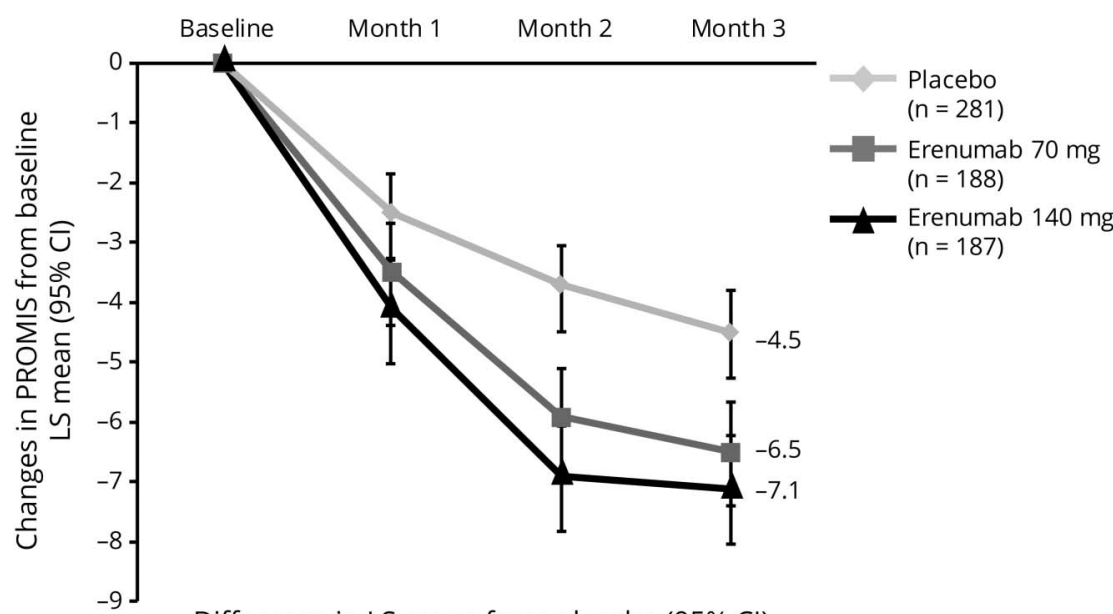

Difference in LS mean from placebo $(95 \% \mathrm{Cl})$

$$
\begin{array}{rrr}
70 \mathrm{mg}-1.0(-2.1,0.1) & -2.2(-3.3,-1.1) & -2.0(-3.1,-0.9) \\
p=0.082 & p<0.001 & p<0.001 \\
140 \mathrm{mg}-1.5(-2.7,-0.4) & -3.2(-4.3,-2.0) & -2.6(-3.8,-1.5) \\
p=0.007 & p<0.001 & p<0.001
\end{array}
$$

Least-squares (LS) mean changes from baseline in PROMIS scores among participants with chronic migraine who were assigned to receive erenumab $70 \mathrm{mg}$, erenumab $140 \mathrm{mg}$, or placebo every month. The error bars represent 95\% confidence intervals (Cls). Figure based on the efficacy analysis set. All $p$ values $\leq 0.01$, except for erenumab $70 \mathrm{mg}$ at month $1, p=0.082$.
PROs, which are established to identify a clinically meaningful change on specific attributes of migraine. This is illustrated by the onabotulinum toxin A data in the PREEMPT (Phase 3 Research Evaluating Migraine Prophylaxis Therapy) studies in which only $27 \%$ of treated patients had both a $\geq 5$-point reduction in HIT- 6 score and a $\geq 50 \%$ reduction in headache days. Furthermore, the different PROs have entirely different scales, measure different domains relevant to patients with migraine, and the MIDs are specific to a given PRO; i.e., clinical relevance for the domain(s) tested is independent of other PROs, such that for an individual patient it is not surprising that the relative change on one PRO might be different than the change on a second or third PRO, which measure different facets of relevance to patients. In addition, the within-patient differences for the PROs were estimated based on a variety of methods (e.g., anchor and distributionbased analyses). Therefore, one would not expect a direct relationship between $\mathrm{MMD} \geq 50 \%$ responder rates and $\mathrm{PRO}$ MIDs. In a preliminary assessment of the relationship between change in PRO score and change in MMD, we found that there was a moderate correlation between change in MMD for each PRO with correlation coefficient $r$ values of approximately +0.5 or -0.5 for all the PROs. However, between-subject variation is also observed based on the scatterplots. Any comparison of PRO "response" with percent migraine reduction in an individual patient will depend on what is most meaningful to a patient. Thus, the quantitative relationship between the level of change in migraine frequency and the level of change in PROs requires a more detailed and nuanced analysis. Overall, these data demonstrate that erenumab yields reductions in migraine frequency that are accompanied by improvements in ability to perform daily activities and reductions in feelings of hopelessness and/ or frustration from the effect of CM. Further studies are required to determine the relationship between the level of change in migraine frequency and the level of change in the PROs to confirm whether the improvement in PROs is mediated by a reduction in headache days.

Clinical trials of parenteral pain treatments consistently report high placebo rates. Similar to the high placebo response seen for the primary and secondary endpoints in the main study, the placebo response rates for the PRO endpoints in this analysis were high. However, even with these large placebo responses, the between-group differences were still clinically relevant.

In previous studies of prevention treatments for CM, topiramate consistently showed significant reductions in $\mathrm{MMD}$, but the effect on HRQoL has been mixed. In one study, MIDAS scores did not significantly improve. MSQ scores were initially improved, but the benefit diminished over time. ${ }^{23}$ A separate study of topiramate found no betweengroup differences for MSQ or HIT-6. ${ }^{24}$ The PREEMPT and PREEMPT 2 studies showed that onabotulinumtoxinA reduced headache days at week 24 by 8.4 days and migraine days by 8.2 days compared to 6.6 and 6.2 days, respectively, in the placebo group. ${ }^{25}$ These changes in headache frequency were paralleled by clinically meaningful treatment differences in total HIT-6 scores (approximately -2.5) and all $3 \mathrm{MSQ}$ domains (MSQ-RFR: 17.0 vs 8.6; MSQ-RFP: 13.1 vs 6.4; MSQ-EF: 17.9 vs 9.5). ${ }^{25,26}$ Results from these different studies reveal that improvements in clinical outcomes (e.g., reductions in $\mathrm{MMD}$ ) are not necessarily linked to improvements in patient functioning or HRQoL. Some medications may reduce $\mathrm{MMD}$ but produce side effects that offset the benefits measured by PROs. 
This large placebo-controlled study demonstrated consistent treatment effects across multiple measures. These effects may be accounted for by the combination of efficacy and tolerability erenumab delivers. However, the results may be limited by the short duration of the study relative to the time that patients will remain on treatment in the real world. Further trials are needed to determine the long-term safety of erenumab and the durability of its effects. Heightened expectations arising from the promise of CGRP targeted therapies and the increased clinical attention in the trial, could lead to overestimation of treatment effects in comparison with real-world treatment. These results are unlikely to differentially influence response to active drug and placebo, however.

Overall, these results demonstrate that erenumab led to sustained, significant improvements that are consistent across multiple measures of HRQoL, social and psychological effect, and disability in patients with CM. A comparison of this number of PRO instruments has not been done in such detail in other migraine preventive trials.

This study provides Class II evidence that erenumab improves HRQoL, headache impact, and disability in patients with CM.

\section{Author contributions}

R.B.L., S.J.T., U.R., S.S., W.F.S., D.K.L., P.D., S.C., D.D.M., R.A.L. interpreted the data and revised the manuscript for content; J.N. wrote the first draft of the manuscript based on an outline developed with all co-authors and revised the manuscript for content.

\section{Study funding}

This study was fully funded by Amgen. Erenumab is codeveloped in partnership with Amgen and Novartis.

\section{Disclosure}

R. Lipton declared consultant fees, honoraria, and/or research grants from Alder, Allergan, Inc., Amgen, Avanir, Biohaven, Dr. Reddy's Laboratories, eNeura, electroCore, Lilly, Novartis, Teva, and Trigemina. He has stock options in eNeura and Biohaven. U. Reuter declared consulting fees from Allergan, Amgen, Autonomic Technologies, Eli Lilly and Co., Novartis, CoLucid, Teva; speaking/teaching fees from Amgen, Novartis, CoLucid; Pharm Allergan, TEVA advisory board for Amgen, Autonomic Technologies, Novartis, Pharm Allergan, TEVA. S. Tepper declared research grants (no personal compensation) from Alder, Allergan, Amgen, ATI, Avanir, Dr. Reddy's, electroCore, eNeura, Scion NeuroStim, Teva, Zosano; consultant and/or advisory board for Acorda, Alder, Alexza, Allergan, Amgen, ATI, Avanir, Axsome, Charleston Laboratories, Dr. Reddy's, electroCore, eNeura, Eli Lilly, GLG, Guidepoint Global, Kimberly-Clark, Novartis, Pernix, Pfizer, Scion NeuroStim, Supernus, Teva, Zosano; stock option from ATI; salary from Dartmouth-Hitchcock Medical Center, American Headache Society; royalties from Springer. S. Silberstein declared consultant/ad board fees from Alder
Biopharmaceuticals, Allergan, Inc., Amgen, Avanir Pharmaceuticals, Inc., Curelator, Inc., Dr. Reddy's Laboratories, eNeura Inc., electroCore Medical, LLC, Lilly USA, LLC, Medscape, LLC, NINDS, Supernus Pharmaceuticals, Inc., Teva Pharmaceuticals, Theranica, and Trigemina, Inc. W. Stewart declared consultant fees from Allergan and Amgen Inc. J. Nilsen is an employee and stockholder of Amgen Inc. D. Leonardi was an employee of and held stock/stock options in Amgen Inc. at the time of the study. P. Desai is an employee and stockholder of Amgen Inc. S. Cheng is an employee and stockholder of Amgen Inc. D. Mikol is an employee and stockholder of Amgen Inc. R. Lenz is an employee and stockholder of Amgen Inc. Go to Neurology.org/N for full disclosures.

\section{Publication history}

Received by Neurology March 15, 2018. Accepted in final form January 10, 2019.

\section{References}

1. Stovner LJ, Hagen K, Jensen R, et al. The global burden of headache: a documentation of headache prevalence and disability worldwide. Cephalalgia 2007;27:193-210.

2. Lipton RB, Manack Adams A, Buse DC, Fanning KM, Reed ML. A comparison of the Chronic Migraine Epidemiology and Outcomes (CaMEO) Study and American Migraine Prevalence and Prevention (AMPP) Study: demographics and headacherelated disability. Headache 2016;56:1280-1289.

3. Bebbington P. The World Health Report 2001. Soc Psychiatry Psychiatr Epidemiol 2001;36:473-474.

4. Buse DC, Manack AN, Fanning KM, et al. Chronic migraine prevalence, disability, and sociodemographic factors: results from the American Migraine Prevalence and Prevention Study. Headache 2012;52:1456-1470.

5. Steiner TJ, Stovner LJ, Birbeck GL. Migraine: the seventh disabler. Cephalalgia 2013; 33:289-290.

6. Blumenfeld AM, Varon SF, Wilcox TK, et al. Disability, HRQoL and resource use among chronic and episodic migraineurs: results from the International Burden of Migraine Study (IBMS). Cephalalgia 2011;31:301-315.

7. Serrano D, Manack AN, Reed ML, Buse DC, Varon SF, Lipton RB. Cost and predictors of lost productive time in chronic migraine and episodic migraine: results from the American Migraine Prevalence and Prevention (AMPP) Study. Value Health 2013;16:31-38.

8. Holland S, Silberstein SD, Freitag F, Dodick DW, Argoff C, Ashman E. Evidencebased guideline update: NSAIDs and other complementary treatments for episodic migraine prevention in adults: report of the Quality Standards Subcommittee of the American Academy of Neurology and the American Headache Society. Neurology 2012;78:1346-1353.

9. Aimovig (Erenumab-aooe) [US Package Insert]. Thousand Oaks: Amgen Inc.; 2018.

10. Tepper S, Ashina M, Reuter U, et al. Safety and efficacy of erenumab for preventive treatment of chronic migraine: a randomised, double-blind, placebo-controlled phase 2 trial. Lancet Neurol 2017;16:425-434.

11. Jhingran P, Davis SM, LaVange LM, Miller DW, Helms RW. MSQ: Migraine-Specific Quality-of-Life Questionnaire: further investigation of the factor structure. Pharmacoeconomics 1998;13:707-717.

12. Jhingran P, Osterhaus JT, Osterhaus JT, Lee JT, Kirchdoerfer L. Development and validation of the Migraine-Specific Quality of Life Questionnaire. Headache 1998;38: 295-302.

13. Cole JC, Lin P, Rupnow MF. Minimal important differences in the MigraineSpecific Quality of Life Questionnaire (MSQ) version. Cephalalgia 2009;29: 1180-1187.

14. Dowson AJ. Assessing the impact of migraine. Curr Med Res Opin 2001;17:298-309.

15. Kosinski M, Bayliss MS, Bjorner JB, et al. A six-item short-form survey for measuring headache impact: the HIT-6. Qual Life Res 2003;12:963-974.

16. Coeytaux RR, Kaufman JS, Chao R, Mann JD, Devellis RF. Four methods of estimating the minimal important difference score were compared to establish a clinically significant change in Headache Impact Test. J Clin Epidemiol 2006;59: 374-380.

17. Yang M, Rendas-Baum R, Varon SF, Kosinski M. Validation of the Headache Impact Test (HIT- ${ }^{\text {TM }}$ ) across episodic and chronic migraine. Cephalalgia 2011;31:357-367.

18. Stewart WF, Lipton RB, Dowson AJ, Sawyer J. Development and testing of the Migraine Disability Assessment (MIDAS) Questionnaire to assess headache-related disability. Neurology 2001;56:S20-S28.

19. Lipton R, Desai P, Sapra S, Buse D, Fanning K, Reed M. How Much Change in Headache-Related Disability Is Clinically Meaningful? Estimating Minimally Important Difference (MID) or Change in MIDAS Using Data from the AMPP Study [Abstract]. Boston: American Headache Society Annual Meeting; 2017. 
20. Amtmann D, Cook KF, Jensen MP, et al. Development of a PROMIS item bank to measure pain interference. Pain 2010;150:173-182.

21. Lipton RB, Varon SF, Grosberg B, et al. OnabotulinumtoxinA improves quality of life and reduces impact of chronic migraine. Neurology 2011;77:1465-1472.

22. Silberstein S, Tfelt-Hansen P, Dodick DW, et al. Guidelines for controlled trials of prophylactic treatment of chronic migraine in adults. Cephalalgia 2008;28:484-495.

23. Dodick DW, Silberstein S, Saper J, et al. The impact of topiramate on healthrelated quality of life indicators in chronic migraine. Headache 2007;47: 1398-1408.
24. Diener HC, Bussone G, Oene JCV, Lahaye M, Schwalen S, Goadsby PJ. Topiramate reduces headache days in chronic migraine: a randomized, double-blind, placebocontrolled study. Cephalalgia 2007;27:814-823.

25. Dodick DW, Turkel CC, DeGryse RE, et al. OnabotulinumtoxinA for treatment of chronic migraine: pooled results from the double-blind, randomized, placebocontrolled phases of the PREEMPT clinical program. Headache 2010;50:921-936.

26. Diener HC, Dodick DW, Aurora SK, et al. OnabotulinumtoxinA for treatment of chronic migraine: results from the double-blind, randomized, placebo-controlled phase of the PREEMPT 2 trial. Cephalalgia 2010;30:804-814. 


\section{Neurology}

\section{Erenumab in chronic migraine: Patient-reported outcomes in a randomized double-blind study \\ Richard B. Lipton, Stewart J. Tepper, Uwe Reuter, et al.}

Neurology 2019;92;e2250-e2260 Published Online before print April 17, 2019

DOI 10.1212/WNL.0000000000007452

\section{This information is current as of April 17, 2019}

\section{Updated Information \& Services}

References

Citations

Subspecialty Collections

Permissions \& Licensing

Reprints including high resolution figures, can be found at: http://n.neurology.org/content/92/19/e2250.full

This article cites 24 articles, 3 of which you can access for free at: http://n.neurology.org/content/92/19/e2250.full\#ref-list-1

This article has been cited by 1 HighWire-hosted articles: http://n.neurology.org/content/92/19/e2250.full\#\#otherarticles

This article, along with others on similar topics, appears in the following collection(s):

\section{All Clinical trials}

http://n.neurology.org/cgi/collection/all_clinical_trials

Class II

http://n.neurology.org/cgi/collection/class_ii

Migraine

http://n.neurology.org/cgi/collection/migraine

Quality of life

http://n.neurology.org/cgi/collection/quality_of_life

Information about reproducing this article in parts (figures,tables) or in its entirety can be found online at:

http://www.neurology.org/about/about_the_journal\#permissions

Information about ordering reprints can be found online:

http://n.neurology.org/subscribers/advertise

Neurology ${ }^{\circledR}$ is the official journal of the American Academy of Neurology. Published continuously since 1951, it is now a weekly with 48 issues per year. Copyright Copyright ( 2019 The Author(s). Published by Wolters Kluwer Health, Inc. on behalf of the American Academy of Neurology.. All rights reserved. Print ISSN: 0028-3878. Online ISSN: 1526-632X.

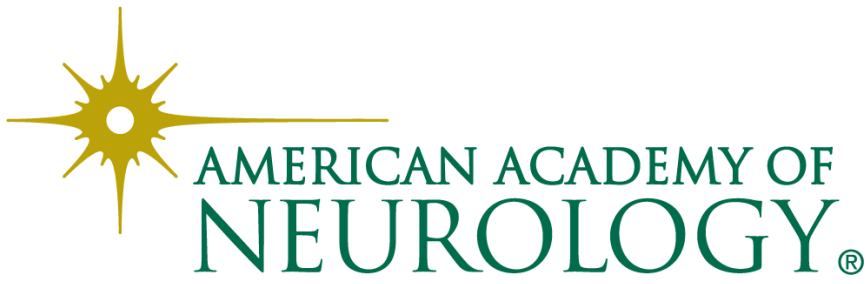

